\section{O Perfeito Cozinheiro de Si Mesmo: a Narrativa Antropofágica de Oswald de Andrade}

\section{Resumo}

O objetivo desta pesquisa é compreender os olhares que Oswald de Andrade lançou sobre a Cidade de São Paulo, tendo como base a obra Os condenados: a trilogia do exílio. Composta por três romances, publicados em intervalos consideráveis, Os condenados nos permite identificar as permanências e transformações da urbe sentidas e apreendidas pelo autor, nos marcos específicos e fundamentais de sua trajetória estética e política.

Palavras-chave: História. Literatura. Cidade. Modernismo. Memória.

\section{Abstract}

The aim of this research is to understand the meanings that Oswald de Andrade built over the city of São Paulo, based on the work Os condenados: a trilogia do exilio. Composed of three novels, published at considerable intervals, Os condenados allows us to identify the permanences and transformations of the city felt and apprehended by the author, in the specific and fundamental milestones of his aesthetic and political trajectory.

Keywords: History. Literature. City. Modernism. Memory.

\section{Introdução}

Pouco antes de sua morte e com a saúde debilitada, Oswald de Andrade não mais vivia com a intensidade da juventude e idade adulta. Suas ações tampouco causavam espanto na sociedade paulistana dos anos cinquenta, tal qual os seus arroubos das décadas de vinte e trinta, seja no âmbito de sua vida privada - de amores sempre públicos numa imprensa que avançava com passos firmes para publicização e espetacularização dos afetos e desafetos -, seja no âmbito cultural e político, com as suas incursões pelo Modernismo de 22 e pelo comunismo a partir de 31. Em seus
Prof. Me. Leonardo da Silva Claudiano

Doutorando em História Social pela Pontifícia Universidade Católica de São Paulo (PUC-SP), com Mestrado em História Social pela mesma instituição. Pesquisador do Núcleo de Estudos de História Social da Cidade (NEHSC/ PUC-SP). Orientadora: Prof. ${ }^{a}$ Dr. ${ }^{a}$ Yvone Dias Avelino.

E-mail: leonardo.claudiano@ gmail.com 
momentos derradeiros, o homem que atravessou as primeiras décadas do século $X X$ em companhia de figuras que se fariam grandes em diversas frentes da história, como Tarsila do Amaral, Mario de Andrade, António de Alcântara Machado, Di Cavalcanti, Victor Brecheret etc., encontrava-se recolhido: a morte levara alguns dos amigos, seu temperamento outros tantos. No entanto, o garoto que cresceu ouvindo da mãe histórias e lendas amazônicas, não encontrou dificuldades para revivê-los na memória, com cores, cheiros e sons de antigamente.

$\mathrm{Na}$ autobiografia Um homem sem profissão,' Oswald nos traz seus primeiros anos e nos conduz até o desfecho de seu relacionamento mais trágico e polêmico, com Maria de Lourdes Dolzani Castro, a Deise ou Miss Cyclone. Seguindo cronologia não ortodoxa, mescla nas lembranças de antes os olhares de agora, com os acertos e erros ponderados, maturados. Analisa eventos da juventude pela ótica antropofágica e marxista de depois. Não se esconde, antes se mostra com escolhas, enaltece feitos e assume culpas - principalmente assume culpas, como no caso da morte de Deise, por um aborto malsucedido - a Tufãozinho, como era também conhecida, "[...] a que encontrei, enfim, para ser toda minha, meu ciúme matou [...]". (ANDRADE, 2002, p. 131) Afirma, mais de trinta anos depois, que as "[...] noites hospitalares (que) nunca mais se apagarão de [sua] minha lembrança [...]". (ANDRADE, 2002, p. 192) No diário mantido por ambos - e por mais alguns frequentadores da garconnière onde se encontravam - batizado como $O$ perfeito cozinheiro das almas deste mundo, encontramos os registros felizes dos primeiros meses do casal e observamos a insinuação do ciúme, que conduzirá ao fatal desfecho. Numa leitura conjunta com as memórias de depois, podemos sentir de forma pungente o peso do erro e da perda que o seguiu por toda sua vida, da "[...] agonia e a morte numa fria madrugada de hospital [...]" (ANDRADE, 2002, p. 193).

1 Publicado em 1954, o projeto inicial contava com cinco volumes, mas a morte o interrompeu.
As memórias de Um homem sem profissão nos dão outras pistas dos olhares que lançou ao redor, do que pretendeu preservar, descartar e recuperar. Pistas que também encontramos no diário da garçonnière e por toda a sua obra. Como afirma Antonio Candido (2002, p. 11):

\footnotetext{
Um escritor que fez da vida romance e poesia, e fez do romance e da poesia um apêndice da vida, publica as suas memórias. Vida ou romance? Ambos, certamente, pois em Oswald de Andrade nunca estiveram separados, e a única maneira correta de entender a sua vida, a sua obra e estas Memórias, é considera-las deste modo.
}

Candido propõe o entendimento da obra de Oswald em sinergia com os acontecimentos de sua vida, uma vez que o autor sempre se expôs em tudo o que escreveu. Não por acaso foi a ponta de lança, o mais combativo da Semana de 22, o que sempre afirmou claramente as suas posições - móveis posições, já que seu comportamento anárquico, que pontuou o espírito modernista, não apenas aglutinou o grupo em torno de si, como o repeliu com críticas sarcásticas ao que considerou desvios e traições. Assim, ao nos debruçarmos no despretensioso e colaborativo diário de sua garçonnière, por exemplo, notamos que os registros de suas experiências amorosas e sociais se fazem numa linguagem telegráfica, enxuta. Uma vez coletivo, os apontamentos do escritor sintetizam em respostas algumas mensagens soltas nas páginas por outros colaboradores, incluindo Deise. É irônico, debochado - por vezes com aquele humor de camaradagem, em outras tantas, ácido, desconcertante. Características que terão reflexos em suas duas obras mais relevantes, Memórias sentimentais de João Miramar - nos ecos mais imediatos de 22; e Serafim Ponte Grande, cuja redação se iniciou ainda na década de vinte, mas que veio a público nos anos 30 , revisto, somando ao olhar antropofágico, as questões sociais através de uma leitura não ortodoxa de Marx. Nas duas obras encontramos frases que sintetizam, humor que cutuca, pois coloca a nu convenções tradicionalistas e burguesas, 
denunciando atrasos e hipocrisias da classe dominante. Assim, temos que:

Todo o processo fragmentário de Oswald nasce dessa experiência pessoal de diarista [...]. O gosto pelo trocadilho, cultivado abusivamente no diário e provindo de Emilio de Menezes, o amor pelas situações insólitas e imprevistas com tons de sátira e humor têm a mesma fonte. (BRITO, 2014, p. 17)

O início desse diário coletivo data de 30 de maio de 1918 e termina no mesmo ano, em 12 de setembro, com parcos preenchimentos posteriores, a ser finalizado com um recorte de jornal de 25 de agosto de 1919, cuja reportagem é sobre a morte de Deise. De inauguração jovial e despretensiosa, o discurso originário, redigido por um dos assíduos frequentadores da histórica garçonnière situada à rua Líbero Badaró, n. ${ }^{\circ}$ 67, terceiro andar, João de Barros (pseudônimo de Pedro Rodrigues de Almeida), define seus cheiros e ingredientes:

Muito de arte entrará nestes temperos, arte e paradoxo, que, fraternalmente, se misturarão para formar, no ambiente colorido e musical deste retiro, o cardápio perfeito para o banquete da vida. (ANDRADE, 2014, p. 1)

O diário, que funciona como laboratório de sua escrita modernista, preanuncia a antropofagia pela qual ficará conhecido (SCHWARTZ, 2014). Mais do que isso, pode igualmente ser lido como o romance trágico, pelo fatal desfecho entre Oswald e Deise. Ainda que coletiva, a personalidade aglutinadora e condutora do escritor se sobressai, e o fio narrativo do casal termina por deixar em segundo plano as demais contribuições.

\section{O perfeito cozinheiro das almas deste mun-} do antecede o Modernismo de 22 e dá contornos da personalidade sarcástica e combativa de um de seus principais líderes. Vida e obra se mesclam e registram fatos de desdobramentos significativos.
Saltando três anos na cronologia, encontramo-nos na Semana de Arte Moderna, onde Oswald é vaiado ao ler trechos de seu primeiro romance, Os condenados, que torna ficcional o caso de amor com Miss Cyclone. Mais do que isso, recorta São Paulo em flashes, na tentativa modernista de abarcar a simultaneidade da cidade, captar a velocidade dos tempos fazendo uso de técnicas de recortes num estilo de escrita cinematográfica. Não se trata, evidente, do grande romance oswaldiano. Entretanto, é o mais intrigante. Os condenados, depois rebatizado de Alma, abre a obra homônima Os condenados: a trilogia do exílio. De imediato, recebeu elogio de seus pares. Com enredo focado em Alma, a cidade é apresentada em ritmo frenético e, além da composição em cortes, temos a modernidade nos novos vocábulos que passam a fazer parte do existir urbano, como motorneiro, operário, telégrafo. Notamos, igualmente, o embate, as fronteiras borradas do tradicional e do novo: Piratininga está em alguns personagens, em algumas sociabilidades e festas religiosas. Oswald, rompendo a máxima então vigente de "literatura como brinde de sobremesa", acrescenta às vivências citadinas o mundo da prostituição e seu vocabulário característico.

O segundo romance da trilogia vem a público em 1927, A estrela do absinto. É a primeira tentativa de expurgo da culpa carregada pelo desenrolar de seu romance com Deise. A narrativa se abre com o mesmo diálogo de quando a conheceu:

$$
\begin{aligned}
& \text { - Que pensa dos homens? } \\
& \text { - Uns canalhas... } \\
& \text { - E das mulheres? } \\
& \text { - Também. (ANDRADE, 2003, p. 159) }
\end{aligned}
$$

Estrela do absinto explora ainda mais o cenário urbano da Cidade de São Paulo. No entanto, os seus aspectos modernos e seus motores à combustão se impõem sobre Piratininga.

2 Segundo o próprio Oswald, todos os volumes foram escritos entre 1917 e 1921. Entretanto, nos hiatos das publicações, o escritor revisitou constantemente os esboços, reescrevendo inúmeros trechos segundo a sua visão contemporânea. 
Automóveis cortam velozmente a Avenida São João e o autor faz questão de nos situar nos espaços públicos (Largo de São Bento, Largo do Paiçandu) e internos, como a garçonnière, cuja descrição repete as pistas decorativas deixadas n'O perfeito cozinheiro das almas deste mundo. Oswald abre cada capítulo com passagens bíblicas, fruto de seu arraigado catolicismo e penitência. A cidade que aparece em simultaneidade é - não obstante a imposição da velocidade dos tempos modernos, dos veículos que rasgam as ruas -, de ritmo cadenciado, lento em muitos momentos, pois os olhos que a filtram e representam são tristes. E vemos a tristeza no inverno frio de julho, nas cores carregadas de cinza, tanto do céu, quanto nos paletós terrenos. Alma morre e a perda, anunciada desde a primeira linha, reforça o sentimento de solidão da urbe que se individualiza cada vez mais.

Por fim, encerrando a Trilogia do exílio, em 1934 sai $\mathbf{A}$ escada vermelha (A escada, na versão final, de 1941). Notamos, pelo batismo, os reflexos de sua adesão ao comunismo. A composição continua em simultaneidade, mas as abordagens deixam entrever, igualmente, o marxismo no trato com os personagens que transitam pelo centro paulistano. A cidade, moderna, é também o palco dos embates entre capital e operário. Assim como Oswald, o personagem principal, Jorge D'Alvelos, torna-se alvo da polícia política. Assim como Oswald, reencontra o amor numa militante revolucionária.

Percorrendo a Trilogia do exílio e ampliando seu entendimento para as vivências do próprio escritor, vemos como a percepção de cidade, modernismo e lutas sociais se preservam e alteram. Toda concepção de mudanças é dialética, de modo que em Alma temos elementos que eclodem mudança em Estrela do absinto e assim de forma sucessiva. A cidade como vivência pequeno-burguesa (Alma), ou a cidade como palco de lutas sociais (A escada vermelha), traz os mesmos elementos que seduzem e assustam. A modernidade é uma experiência dialética e encontramos por toda obra oswaldiana esse registro perceptivo.

\section{Objetivos e metodologia}

Como pudemos notar na breve introdução, a Trilogia do exílio possui marcos temporais que estabelecem diálogos importantes com a vida de Oswald. Assim, para cada baliza cronológica das publicações, pretendemos trazer ao encontro outras obras do autor de momentos limítrofes:

- Os condenados (Alma) (1922):

- O perfeito cozinheiro das almas desse mundo (1918);

- Memórias sentimentais de João Miramar (1924);

- Manifesto da Poesia Pau Brasil (1924);

- Cancioneiro Pau Brasil (1925).

- Estrela do Absinto (1927):

- Primeiro caderno de poesia do aluno Oswald de Andrade (1927):

- Manifesto Antropófago (1928);

- Serafim Ponte Grande (1933): o primeiro prefácio da obra é de 1926, o término em 1929 e a publicação é de 1933. Pelos prefácios escritos em momentos distintos, pode-se notar a aproximação de Oswald com o comunismo. É igualmente importante destacar que Serafim foi escrito quando o autor tinha como companheira Tarsila do Amaral, sendo editado e publicado com Patrícia Galvão, que em 1933 entregou Parque industrial. O segundo prefácio de Serafim Ponte Grande tem laços com o romance de Pagu.

- A escada vermelha (A escada) (1934):

- Jornal: o homem do povo (1931);

- Serafim Ponte Grande (1933);

- O rei da vela (1937)

Percorrendo esse organograma inicial, as obras anteriores ao Perfeito cozinheiro das almas desse mundo (1918), como o semanário O Pirralho (1911) e as produções posteriores a $O$ rei da vela (1937), como Marco zero I: a 
revolução melancólica (1943), Marco zero II: chão (1945) e Um homem sem profissão: memórias e confissões - sob as ordens de mamãe (1954), também estarão em diálogo. Ainda que a metodologia estabeleça e nomeia obras bases, ressaltamos que as fontes primárias percorrerão todo o estudo, uma vez que não existem fronteiras entre os aspectos a serem abordados. Com isso, buscamos os seguintes objetivos:

- Investigar como a Cidade de São Paulo, em seu processo modernizante, foi percebida por Oswald de Andrade através de sua produção pré (textos na imprensa, principalmente no jornal O Pirralho) e Pós-Semana de Arte Moderna [com foco no romance Os condenados: trilogia do exílio, que compila os romances Os condenados/Alma (1922); Estrela de Absinto (1927) e A escada (1934)];

- Compreender os reflexos em sua produção das relações pessoais, culturais e políticas que estabeleceu, tais como no círculo modernista de 22 [pela obra Memórias sentimentais de João Miramar (1924)]; e nos círculos anarquista e comunista dos anos trinta [principalmente através da investigação do periódico 0 homem do povo e do romance Serafim Ponte Grande (1933)];

- Analisar a representação de Modernismo, de cidade e de lutas sociais, que preservou em seus escritos ao longo do tempo, quando das influências em suas vivências das adesões culturais e políticas.

\section{Considerações finais}

Resgatar Oswald, sua obra e vida, mostra-se fundamental pela possibilidade de investigar, via literatura, os anos que viveu. A utilização da obra literária como fonte histórica, enriquece e contribui para o debate historiográfico e esse diálogo entre campos de conhecimento distintos, porém próximos, abre a possibilidade de irmos ao cotidiano mais miúdo e colocá-los em diálogo com os movimentos amplos da História. Alma, mulher pobre, por exemplo, torna-se sujeito histórico e isso guarda reflexos no presente, uma vez que a consciência de historicidade também nos é revelada. Assim situados, agimos e resistimos, conforme se apresentam as circunstâncias. Walter Benjamin (2012) nos lembra da relevância do cronista, na importância que seus registros possuem para a História. Igualmente, alerta-nos de que relembrar os antigos é homenagear suas lutas e revivê- las em contemporaneidade. A História, na aproximação metodológica que pode e deve realizar em direção à Literatura, faz jus aos apontamentos de Benjamin

A amplitude de fontes nas quais o historiador pode se debruçar para perscrutar o passado, permite abordagens e resultados inéditos, trazendo à tona falas e vivências, muitas vezes, de grupos periféricos - elementos humanos que transitavam nas margens da história, não participando do êxito dos acontecimentos, do sucesso dos fatos (SEVCENKO, 2003).

A literatura - no caso a literatura brasileira moderna, abordada pelo nosso estudo de temáticas e inovações discursivas, de uma nova forma de se pensar e agir esteticamente, não mais como instrumento propagandístico de prazeres sociais e prática relaxante nos momentos de lazer, não mais como o "sorriso da sociedade", mas sim como elemento de denúncia crua ou cômica, como plataforma de propostas e projetos, tanto nacionais como universais (BOSI, 2006) - a literatura moderna, dizíamos, constitui-se, pelo exposto, de elemento fundamental nas buscas pessoais e coletivas de grupos marginais. Por conseguinte, desvendamos, também, as práticas e negociatas do poder que deliberadamente conservaram (conservam) às periferias grande parte do contingente populacional.

No entanto, por ser ficção, ainda que pautada nos elementos do real, a literatura deve ser trabalhada não como espelho, mas como refração (ELEUTÉRIO; AVELINO, 1992). Em outras palavras, o texto literário trata daquilo que é, porém, com o recurso discursivo daquilo que não foi e que poderia ter sido. Desta forma: 
O historiador não pode encarar a obra literária apenas como veículo de conteúdo, pois o valor do texto literário não está propriamente na confrontação que dele se pode fazer com a realidade exterior, mas na maneira como esta realidade é abordada, aprofundada, questionada, recriada. (AVELINO, 2012, p. 249)

Principalmente, é pela acentuação da falta, de maneira dramática ou satirizada, que o texto literário relata ao historiador a ausência, não só material de determinado grupo, mas de oportunidades que se pensam e não se concretizam por questões político-econômicas. É Sevcenko (2003, p. 30) quem afirma:

\begin{abstract}
A literatura fala ao historiador sobre a história que não ocorreu, sobre as possibilidades que não vingaram, sobre os planos que não se concretizaram. Pode-se, portanto, pensar numa história dos desejos não consumados, dos possíveis não realizados, das ideias não vingadas.
\end{abstract}

Trazer "a história que não ocorreu": resgatar, pelas letras de Oswald de Andrade, as transformações e experiências das múltiplas modernidades dos anos 20 e 30 na Cidade de São Paulo; resgatar o impacto da tecnologia, da velocidade e do urbanismo excludente.

Para pesquisa historiográfica cuja fonte é a literatura, a figura do literato não pode ser desprezada. Principalmente a da envergadura de Oswald de Andrade. Seu círculo intelectual, as técnicas narrativas, temáticas e formas de abordagem - dramáticas, líricas, cruas ou debochadas - são chaves que revelam seus valores estéticos e, por conseguinte, pessoais. Homem, literato e obra são elementos cujo diálogo deve ser ininterrupto.

Assim, um ciclo se cria, revelando respostas e novas perguntas: imergindo na obra de Oswald, no homem e artista, dirigimo-nos ao cotidiano da São Paulo dos anos vinte e trinta pelos caminhos de inúmeras obras ficcionais ou não. E colhemos aspectos culturais e políticos que até hoje nos ecoam.
Resgatar Oswald também é fundamental para o nosso presente, que insiste em flertar com práticas autoritárias aparentemente não superadas. "Como poucos, eu conheci as lutas e as tempestades. Como poucos eu amei a palavra liberdade e por ela briguei". (ANDRADE, 2002, p. 52)

\section{Referências bibliográficas}

ANDRADE, O. O perfeito cozinheiro das almas deste mundo. São Paulo: Globo, 2014.

Um homem sem profissão, memórias e confissões: sob as ordens de mamãe. São Paulo: Globo, 2002.

Os condenados: a trilogia do exílio. São Paulo: Globo, 2003.

AVELINO, Y. D. Os labirintos da arte de narrar: História e Literatura. In: CARVALHO, A. M.; FLORIO, M.; AVELINO, Y. D. História, cotidiano e linguagem. São Paulo: Expressão e Arte, 2012.

BENJAMIN, W. Obras escolhidas I. São Paulo: Brasiliense, 2012.

BOSI, A. História concisa da literatura brasileira. São Paulo: Cultrix, 2006.

BRITO, M. da S. O perfeito cozinheiro das almas deste mundo. In: ANDRADE, O. O perfeito cozinheiro das almas deste mundo. São Paulo: Globo, 2014.

CANDIDO, A. Prefácio inútil. In: ANDRADE, O. Um homem sem profissão, memórias e confissões: sob as ordens de mamãe. São Paulo: Globo, 2002.

ELEUTÉRIO, M. de L.; AVELINO, Y. D. O bosque sagrado e o borrado. Projeto História, São Paulo, n. 8/9, 1992.

SEVCENKO, N. Literatura como missão. São Paulo: Companhia das Letras, 2003.

SCHWARTZ, J. O perfeito cozinheiro das almas deste mundo: diário ou ficção. In: ANDRADE, O. O perfeito cozinheiro das almas deste mundo. São Paulo: Globo, 2014. 